\title{
Prostate Undifferentiated Carcinoma
}

National Cancer Institute

\section{Source}

National Cancer Institute. Prostate Undifferentiated Carcinoma. NCI Thesaurus. Code C5597.

An invasive prostate carcinoma characterized by the presence of undifferentiated malignant cells. 